albino over wild $F_{1}$ rats as the longer ITI is increased beyond $100 \mathrm{sec}$.

Previous research suggested that an inflexible neophobic type of responding was the primary deterrent to the development of a high level of conditioning in wild rats (Boice, 1968). In the present study, shuttlebox behaviors in undomesticated rats were comparatively stereotyped and rigid. For instance, ITI behaviors in the undomesticated rats were typified by a complete lack of movement until the ensuing trial. Intertrial interval behaviors in the albino rats were rigid only until avoidance responding began, and then grooming, sniffing, and other movements became the rule. Thus, while the transition from escape to avoidance learning in the domesticated rats is seemingly accompanied by "disinhibiting" behaviors (cf. Fentress, 1968), the undomesticated rats do not show similar behavioral changes. The inhibitory response style of the wild rats was probabiy related to a comparatively high state of emotion. Of a variety of behaviors observed in the shuttlebox, squealing responses differentiated the groups most clearly. The albino rats appeared to be the least emotional group and, accordingly, had the lowest level of squealing (Fig. 1). Prior observations had indicated that the wild $F_{1}$ rats would squeal more than the wild-caught rats. This may mean that the early experience of confinement in captivity for a genetically wild rat is critically different from confinement following early experience in nonconfinement.

Clearly, the emotionality of the wild rat does not suit it to learn a two-way shuttlebox task or, possibly, any conventional laboratory learning task. Barnett (1967) notes that, although stereotyped neophobic behaviors in the wild rat have obvious survival value, they are "automatic," undiscriminating, and not "intelligent" behaviors. Wild animals appear to occupy niches where unexpected events are rare (Kavanau, 1967). Observations of wild rats indicate that learning is atypical in adulthood. Thus, it is conceivable that only in domestication, where the preoccupation is with boredom and not predation (Hediger, 1964), will an animal acquire both the ecotype and the genotype to encourage a continual emphasis on learning behaviors.

The results of this study suggest that domestication has not caused a decrease in the learning ability of the Norway rat. Moreover, it indicates that domesticated rats may be suitable for use in formulation of basic learning principles, especially where generalization is to domesticated man. Undomesticated rats might then be studied for such richer behaviors as aggression in situations where evolutionary principles are sought.

\section{REFERENCES}

BARNETT, S. A. Instinct and intelligence Behavior of animals and man. Englewood Cliffs, N.J: Prentice-Hall, 1967.

BEACH, F. A. The snark was a boojum. American Psychologist, 1950, 5, 115-124.

BOICE, R. Conditioned licking in wild $F_{1}$ and domestic Norway rats. Journal of Comparative \& Physiological Psychology, 1968, 66, 796-799.

BOICE, R., \& BOICE, C. Trapping Norway rats in a land fill. Journal of the Scientific Laboratories, Denison University, 1968, 49, 14 .

BOICE, R., DENNY, M. R., \& EVANS, T. A comparison of albino and wild rats in shuttlebox avoidance. Psychonomic Science, 1967, 8, 271-272.

DENNISTON, R. H. Escape and avoidance learning as a function of emotionality level in the Wyoming ground squirrel, Citellus richardsonii elegans. Animal Behaviour, 1959, 7, 241-243.

DENNY, M. R. Relaxation theory and experiments. In F. R. Brush (Ed.), Aversive conditioning and learning. New York: Academic Press, 1969.

HEDIGER, H. Wild animals in captivity. New York: Dover, 1964.

FENTRESS, J. C. Interrupted ongoing behaviour in two species of vole (Microtus agrestis and Clethrionomys britannicus). I. Response as a function of preceding activity and the context of an apparently 'irrelevant' motor pattern. Animal Behaviour, 1968, 16, 135-153.
KAVANAU, J. L. Behavior of captive white-footed mice. Science, 1967, 155, 1623-1639.

LOCKARD, R. B. The albino rat: A defensible choice or a bad habit? American Psychologist, $1968,23,734-742$.

ROBINSON, R. Genetics of the Norway rat. Oxford: Pergamon Press, 1965.

STONE, C. P. Wildness and savageness in rats of different strains. In K. S. Lashley (Ed.), Studies in the dynamics of behovior. Chicago: University of Chicago Press, 1932.

TIGHE, T. J. A handling device for small animals. Journal of the Experimental Analysis of Behavior, 1965, 8, 261.262.

TINBERGEN, N. Animal behavior. New York: Time, Inc., 1965.

WEISMAN, R. G., DENNY, M. R., \& ZERBOLIO, D. J. Discrimination based on differential nonshock confinement in a shuttlebox. Journal of Comparative \& Physiological Psychology, 1967, 63, 34-38.

\section{NOTES}

1. This study was supported by Grant MH-16093-01 from the National Institute of Mental Health. The author acknowledges the assistance of Dr. Carol Boice and Janet A. Witter.

2. Requests for reprints should be sent to R. Boice, Department of Psychology, 209 McAlester Hall, University of Missouri, Columbia, Mo. 65201 .

3. Only the albino rats required temporary shock intensity increases to produce running to shock onset. In a previous study (Boice, Denny, \& Evans, 1967), failure to prevent "freezing" responses in albino rats produced an equivocal comparison of avoidance behaviors in domesticated and undomesticated rats.

\title{
Amnesia from ECS: The effect of pairing ECS and footshock ${ }^{1}$
}

JOHN L. JAMIESON and D. J. ALBERT, University of British Columbia, Vancouver, B.C., Canada

An attempt was made to repeat the finding of Schneider \& Sherman (1968) that apparent amnesia results from the pairing of footshock and ECS independently of passive-avoidance training. Pairing of footshock and ECS $5 \mathrm{~h}$ after training was not found to cause a retention deficit, whereas ECS immediately - after training resulted in memory loss. This result shows that the "aftereffects" demonstrated by Schneider and Sherman are not general enough to account for all reported ECS-induced amnesia.

The lack of retention shown by animals receiving electroconvulsive shock (ECS) shortly after training has been taken as evidence that memory requires a period of time to consolidate (see McGaugh, 1966). Recently, Schneider \& Sherman (1968) have demonstrated that apparent amnesia can be produced by the temporal contiguity of footshock and ECS independent of the training-ECS interval. They showed that ECS $.5 \mathrm{sec}$, but not $30 \mathrm{sec}$, after training on a step-down task produced amnesia; they then went on to show that ECS $6 \mathrm{~h}$ after training also produced amnesia when it followed a footshock by $.5 \mathrm{sec}$ but not $30 \mathrm{sec}$. Schneider and Sherman suggest that the temporal contiguity of footshock and ECS produces "aftereffects" that impair performance of a freezing response, thus giving the appearance of amnesia for the passive-avoidance training. Deutsch (1969) 
has used this recently as a pivotal finding in reinterpreting the evidence on consolidation. He suggests that ECS may not produce a retrograde memory deficit at all.

The present study is an attempt to demonstrate ECS-induced amnesia while controlling for a possible interaction of ECS and footshock. The task used (passive avoidance of a drinking response) involved a response less influenced by extraneous variables than the step-down response. Higher levels of footshock and ECS were also employed, and the ECS was administered directly to the brain via screw electrodes. It was felt that these conditions would maximize the possibility of demonstrating true amnesia.

\section{METHOD}

Thirty-two male hooded rats, weighing 230-300 g, were used. They were housed individually and kept on 23-h water deprivation throughout the experiment. For the first week, they were handled and trained to drink from the water spout in an alley. The alley was $4 \mathrm{ft}$ long and 8 in. wide, with a grid floor and a water spout protruding through one end wall. On the day following pretraining, the animals were anesthetized (sodium pentobarbital), and small stainless steel screws attached to connecting wires were turned just through the skull bilaterally at a location $1.0 \mathrm{~mm}$ posterior to bregma and $4.0 \mathrm{~mm}$ lateral. Dental acrylic was then applied to cover the screws and the wound area so that only the connecting wires protruded.

On the day following surgery (Day 1), the animals were placed at the end of the alley opposite the drinking spout, and the latency to drink was recorded manually. The animals were left in the alley for $1 \mathrm{~min}$, regardless of whether drinking occurred or not. If drinking did not occur, the animal was assigned a score of $60 \mathrm{sec}$. Three trials, spaced $30-45 \mathrm{~min}$ apart, were given. On the following day (Day 2), the identical procedure was followed except that cables for administering ECS were attached during the last two trials.

On the basis of their drinking latencies on the first 2 days, four matched groups of eight animals each were formed. On Day 3, all animals were given one trial with the ECS cables attached. As soon as they touched the water spout, a $1-\mathrm{sec}, 2.0-\mathrm{mA}$ footshock was applied. One group received no ECS; a second group received ECS immediately (within $0.5 \mathrm{sec}$ ) after the footshock. The animals in the third group were returned to their home cages for $1 \mathrm{~h}$ before being given ECS. The last eight animals were returned to their home cages for $5 \mathrm{~h}$, then placed on the grid floor in front of the water spout and administered a $1-\mathrm{sec}, 2.0-\mathrm{mA}$ footshock followed, within
$0.5 \mathrm{sec}$, by ECS. In ail cases, the ECS current was between 100 and $120 \mathrm{~mA}$ for $0.5 \mathrm{sec}$. Four $\mathrm{Ss}$ were disubled as a result of the ECS and were discarded from the experiment. On Day 4, the remaining animals were given three trials, as on Day 1.

\section{RESULTS}

For each animal, the three latencies to drink on each day were averaged and the medians for each group plotted in Fig. 1 . All the groups except the immediate-ECS group showed significantly longer latencies on Day 4 than on Day 2 (all ps $<.05$, Wilcoxon tests, two-tailed). The immediate-ECS group $(\mathrm{N}=7)$ did not show significant avoidance, while the 1-h-ECS group $(N=6)$ did, thus demonstrating the usual temporal gradient of ECS-induced amnesia. The group receiving the footshock and ECS pairing at $5 \mathrm{~h}(\mathrm{~N}=7)$ also showed good retention, contrary to the finding expected from the Schneider and Sherman experiment.

To determine whether or not the groups showing retention differed in the strength of the avoidance learning, these animals were given three trials on Day 5 to examine any possible differences in the rates of extinction. The median latencies for Day 5 are also presented in Fig. 1. The data showed that both the no.ECS and the 1-h-ECS groups had significantly lower latencies on Day 5 than on Day $4(p<.05$, Wilcoxon, two-tailed). The 5-h-footshock-ECS group, on the other hand, did not show extinction but, instead, had significantly longer latencies than the no-ECS group $(\mathrm{p}<.05$, median test, two-tailed).

\section{DISCUSSION}

In this experiment, ECS following $.5 \mathrm{sec}$, but not $1 \mathrm{~h}$, after training produced amnesia, while pairing of footshock and

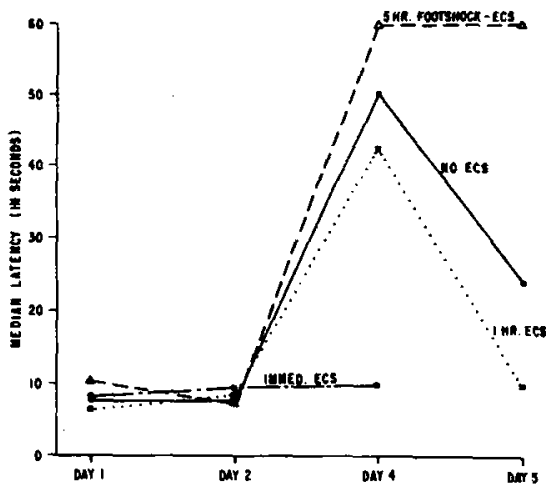

Fig. 1. Median latencies to drink on the 2 days before and after passive-avoidance training (Day 3). See text for explanation of groups.
ECS $5 \mathrm{~h}$ atter training did not. These results suggest that ECS following $.5 \mathrm{sec}$ after training produced an amnesia that was due to disruption of a memory consolidation process rather than to "aftereffects" resulting from the pairing of footshock and ECS.

This questions the generality of the effect observed by Schneider \& Sherman (1968) and suggests that Deutsch's (1969) reevaluation of the ECS literature may have been premature. Moreover, an early study by McGaugh (1966) and a more recent report by Banker (1969) both provide data inconsistent with Schneider and Sherman's finding. However, two other studies (Misanin, Miller, \& Lewis, 1968; and Davis \& Klinger, 1969) report findings somewhat similar to Schneider and Sherman's. Until the conditions necessary for the appearance of this phenomenon have been clarified, it must be controlled for in experiments investigating the consolidation process. At the same time, the present experiment emphasizes that the simple pairing of ECS and footshock cannot account for the entire retrograde effect of ECS.

In the present study, the footshock-ECS pairing at $5 \mathrm{~h}$ not only did not eliminate the effect of the original training, but substantially added to it. Why the ECS should be ineffective in eliminating the added effect of the second footshock is unclear. A possible clue might lie in the observation that these animals exhibited a high level of arousal when placed on the grid $5 \mathrm{~h}$ after initial training. This arousal might have served either to strengthen the initial learning or to speed up the consolidation of the second footshock.

\section{REFERENCES}

BANKER, G. Evidence supporting the memory disruption hypothesis of electroconvulsive shock action. Paper presented at Western Psychological Association, Vancouver, B.C., Canada, June 1969.

DAVIS, R. E., \& KLINGER, P. D. Environmental control of amnesic effects of various agents in goldfish. Physiology \& Behavior, 1969, 4, 269-271.

DEUTSCH, J. A. The physiological basis of memory. Annual Review of Psychology, 1969, 20, 85-102.

McGAUGH, J. L. Time-dependent processes in memory storage. Science, 1966, 153, 1351-1358.

MISANIN, J. R., MILLER, R. R., \& LEWIS, D. J. Retrograde amnesia produced by electroconvulsive shock after reactivation of a consolidated memory trace. Science, 1968. 160, 554-555.

SCHNEIDER, A. M., \& SHERMAN, W. Amnesia: $A$ function of the temporal relation of footshock to electroconvulsive shock. Science, 1968, 159, 219-221. NOTE

1. This research was supported by grants to D. J. Albert from the National Research Council (APA 192) and the University Research Committee. 